\title{
Caring for the mother-child dyad as a family physician
}

\author{
Li Ping Marianne Tsang ${ }^{1}$, MBBS, MRCP, David Chee Chin $\underline{N g}^{1,2}$, MMed, FCFP, Yoke Hwee Chan ${ }^{3,4}$, MBBS, MRCP,
} Helen Yu $\underline{\mathrm{Chen}}^{4,5}$, MMed, Dip(Psychotherapy)

\begin{abstract}
At Adam's 12-month vaccination, your clinic nurse highlighted that his mother, Sara, seemed preoccupied in the waiting area. Adam began to cry but Sara only responded when his wails grew louder. She pushed his pacifier into his mouth rather mechanically and rocked his stroller back and forth on the spot. When they entered your room, Sara seemed rather stiff as she lifted Adam up from his stroller for your examination. Adam sat still in her lap, sucking his pacifier as he stared blankly at the Snellen chart on your clinic wall. He did not make any sound throughout the consultation. Sara looked tired and gave brief answers when asked about Adam's development.
\end{abstract}

\section{WHAT IS THE MOTHER-CHILD DYAD?}

The mother-child dyad - the mother-offspring unit - share an intimate biological, social and psychological relationship. It is no surprise that infant social, emotional and neurological development is shaped by the bond established between mother and child. The quality of this attachment, often reflected in the level of maternal emotional availability, maternal sensitivity and responsiveness to infant cues, determines how infants learn, form relationships, experience the world and regulate their emotions. For example, young children demonstrate 'social referencing', in that they use parents' emotional expressions as guides in approaching or withdrawing from physical and social stimuli. ${ }^{(1)}$ In an unfamiliar situation, a mother's emotional availability has a positive effect on the infant's affective, social and exploratory behaviours. Conversely, a physically present but emotionally unavailable mother invokes displeasure and inhibits her child's exploration. ${ }^{(2,3)}$

Infants who learn that their social initiatives are successful in getting a reciprocal response from their attachment figure are likely to be more secure, active and happy in their interactions; they also show more attentional engagement with their caregiver, fewer resistant behaviours and greater physiological regulation in response to stress. ${ }^{(4)}$ Mothers do not need to be perfect, just 'good enough' to provide a secure base. ${ }^{(5)}$

\section{WHY IS THIS IMPORTANT TO MY PRACTICE?}

Maternal mental health is closely linked to child mental health and development. One in eight mothers experience postpartum depression. ${ }^{(6)}$ Mothers with depression have been found to be less attuned to their infant's needs, demonstrate poorer responsiveness to infant cues, and display more negative, hostile or disengaged parenting behaviours. This is in turn associated with lower cognitive functioning and adverse emotional development in their children. ${ }^{(7,8)}$

Short lapses in caregiving can be compensated for, but persistent attachment difficulties can cause longstanding ramifications. This is because neuroplasticity is highest in the first thousand days of a child's life, beyond which it becomes progressively harder to reverse any adverse adaptations that the child may have made in response to its mother's lack of attunement. ${ }^{(9)}$ Children whose mothers had persistent and severe depression (as compared to children of mothers with transient postnatal depression) were at increased risk of behavioural problems by age 3.5 years, increased risk of depression in adolescence $^{(10)}$ and increased risk of stunted growth. ${ }^{(3,11)}$

\section{WHAT ARE THE RED FLAGS AND RISK FACTORS TO LOOK OUT FOR?}

Risk factors for dysfunction in the mother-child dyad include medical and psychiatric illness in both mother or child, as well as challenging socioeconomic circumstances. ${ }^{(12)}$ Red flags to look out for include reduced maternal attunement, reduced child responsiveness to the mother, and restricted child growth and development (Table I). The family physician should also be cognisant of injury patterns suggestive of physical child abuse, which is beyond the scope of this article but was discussed in a previous Practice Integration and Lifelong Learning article on management of child abuse. ${ }^{(13)}$

\section{WHAT CAN I DO IN MY PRACTICE?}

The family physician is well-positioned to identify at-risk or dysfunctional mother-child dyads, and intervene to change the trajectory through touchpoints such as scheduled well-child developmental assessments, the routine postnatal check and ad-hoc consultations for acute illnesses.

\footnotetext{
${ }^{1}$ SingHealth Polyclinics, ${ }^{2}$ SingHealth Duke-NUS Family Medicine Academic Clinical Programme, ${ }^{3}$ Division of Medicine, KK Women's and Children's Hospital, ${ }^{4}$ Duke-NUS Medical School, '5epartment of Psychological Medicine, KK Women's and Children's Hospital, Singapore

Correspondence: Dr Li Ping Marianne Tsang, Resident, SingHealth Polyclinics, 167 Jalan Bukit Merah Connection One (Tower 5), \#15-10, Singapore 150167. marianne.tsang@gmail.com
} 
Table I. Red flags for dysfunction in the mother-child dyad.

\begin{tabular}{|c|c|c|}
\hline Factor & Mother & Child \\
\hline Red flags & $\begin{array}{l}\text { Reduced maternal attunement } \\
\text { - Blunted affect } \\
\text { - Reduced eye contact with child/doctor } \\
\text { - Lack/delayed response to child's cries } \\
\text { - Tearful appearance } \\
\text { - Irritability }\end{array}$ & $\begin{array}{l}\text { Reduced child responsiveness to mother } \\
\text { - Infant lacking eye contact with mother } \\
\text { - Infant irritability/fussiness } \\
\text { - Resistant behaviour } \\
\text { - Infant rejecting mother after separation } \\
\text { Restricted growth and development } \\
\text { - Language delay } \\
\text { - Global developmental delay } \\
\text { - Failure to thrive }\end{array}$ \\
\hline Risk factors ${ }^{(13)}$ & $\begin{array}{l}\text { - Adolescent mother } \\
\text { - Single mother } \\
\text { - Unwanted pregnancy } \\
\text { - Low maternal education or intelligence level } \\
\text { - Low parental socioeconomic status } \\
\text { - History of depression in mother } \\
\text { - Maternal catastrophic illness, e.g. cancer } \\
\text { - Maternal substance abuse }\end{array}$ & $\begin{array}{l}\text { - Autism spectrum disorder } \\
\text { - Trisomy } 21 \text { or other congenital malformations } \\
\text { - Sensory deficits, e.g. visual or hearing impairment } \\
\text { - Adopted child }\end{array}$ \\
\hline
\end{tabular}

Simple tips to support the new mother (Box 1) are especially beneficial as a first step, and remain useful in mothers who decline referral to mental or emotional health services. The family physician can support mother-child interaction by encouraging the mother to talk positively in a gentle tone to the baby; this can nudge the dyad in a healthier direction.

Scheduled well-child developmental assessments are an opportune time for the family physician to screen the mother for postnatal depression, as recommended by the American Academy of Pediatrics. ${ }^{(14)}$ In Connecticut, a well-established programme sited at a community health centre screens mothers for depression during pregnancy, at the routine six-week postpartum visit and during the infants' well-child visits. ${ }^{(15)}$ Locally, the Integrated Maternal Child Wellness Programme, a novel collaboration between SingHealth Polyclinics and KK Women's and Children's Hospital's (KKH) Department of Paediatric Medicine and Women's Mental Wellness Service, uses a two-question screen (Patient Health Questionnaire 2) for maternal depression during scheduled well-child visits at Punggol Polyclinic (Fig. 1). ${ }^{(16)}$ If the mother is not present (e.g. if the child is accompanied by the grandparents or domestic helper), the physician can enquire about the mother's well-being and encourage her to visit the clinic. Further details on what to do if the screening is positive can be found in a previous Practice Integration and Lifelong Learning article on postnatal depression. ${ }^{(16)}$

Early identification of mothers with depression is important so that they can be connected to services that might mitigate the impact of the depression on the mother-child dyad. Studies of maternal depression screening in paediatric practice suggest that (a) it is feasible; (b) it yields a significant number of mothers who require intervention; and (c) intervention is effective, translating into positive child outcomes. ${ }^{(15)}$ Locally, a screening and early intervention programme for postnatal depression in $\mathrm{KKH}$ (established since 2008) has shown improved clinical outcomes in the affected mothers' symptoms, function and quality of life. ${ }^{(17)}$
Box 1. Tips for mothers on emotional wellness after childbirth:

1. Getting into a routine

Establishing a schedule is helpful but there is a need to allow for flexibility, as the baby's needs may change.

2. Taking time for self-care

Allow time to rest and relax, e.g. going for a walk or enjoying entertainment.

3. Eating well and exercising

Good nutrition and exercise helps improve energy levels and well-being.

4. Talking to someone

Confiding in a spouse, family member or trusted friend is helpful to release emotional tension.

5. Writing thoughts down

This helps the mother to reflect and make sense of the lifechanging experience of motherhood.

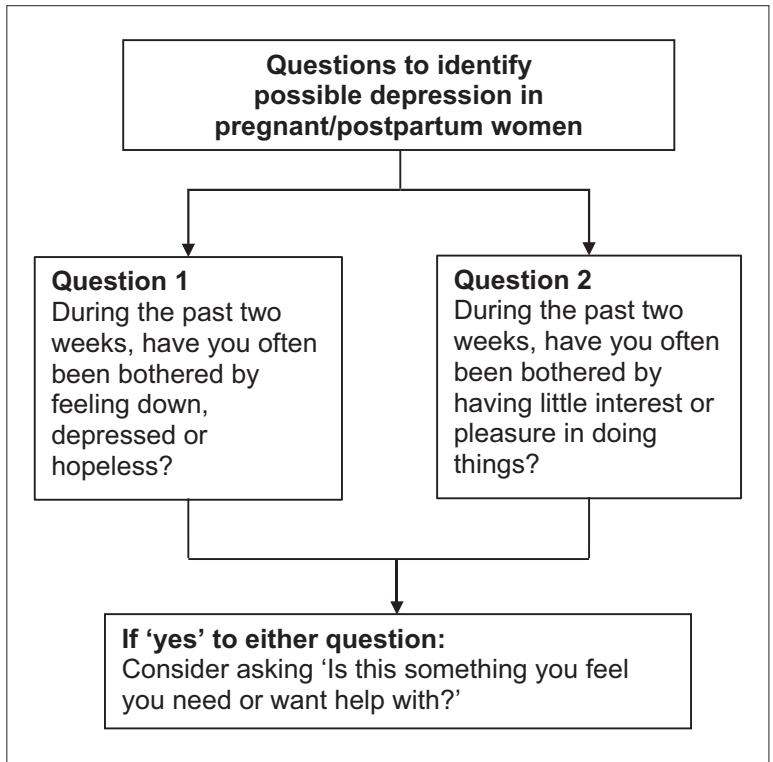

Fig. 1 The Patient Health Questionnaire 2 screen for maternal depression. 
Table II. Safety net of resources according to type of help provided.

\begin{tabular}{|c|c|c|}
\hline Level & Type of help & Examples \\
\hline \multirow[t]{2}{*}{ Informal } & - Social network & Spouse, family, friends, colleagues, religious groups \\
\hline & - Online self-help resources & HealthHub SG (via Web portal/mobile application) \\
\hline \multirow{13}{*}{ Community } & - Counselling & • Family Service Centres \\
\hline & & • Telephone counselling hotlines: \\
\hline & & - Institute of Mental Health's mental health hotline \\
\hline & & - Singapore Association for Mental Health \\
\hline & & - Counselling and Care Centre \\
\hline & & - Fei Yue Counselling Centre \\
\hline & & - Samaritans of Singapore \\
\hline & & - Association of Women for Action and Research \\
\hline & & - Parentline (specifically for parents with \\
\hline & & parenting and childcare issues) \\
\hline & & - Clarity Singapore \\
\hline & - Multidisciplinary support programmes for & - KidSTART (by Early Childhood Development Agency) \\
\hline & young children from vulnerable families & • KIDS 0-3 (by Temasek Cares) \\
\hline \multirow[t]{7}{*}{ Specialist } & - General psychiatry & Psychiatric referral to restructured hospitals \\
\hline & - Maternal mental health & - Postnatal Depression Intervention Programme, \\
\hline & & $\begin{array}{l}\text { Women's Mental Wellness Service (by KK Women's } \\
\text { and Children's Hospital [KKH]) }\end{array}$ \\
\hline & & -Women's Emotional Health Service (by National \\
\hline & & University Hospital) \\
\hline & - Mother-infant therapy & SURE MUMS (SUpporting Resilience and \\
\hline & & Empowering MUMS, home-based therapy by KKH) \\
\hline
\end{tabular}

\section{WHAT RESOURCES ARE AVAILABLE FOR MOTHER-CHILD DYADS?}

At an informal level, the family physician can encourage the mother to engage her spouse and family for support, especially senior members for their advice and experience. Enlisting the help of friends, colleagues or religious group members (educating and equipping them if necessary) can also be useful. Community support resources include Family Service Centres, counselling hotlines, community mental health services and other support programmes (Table II). KKH also offers home-based motherinfant therapy under the SURE MUMS (SUpporting Resilience and Empowering MUMS) programme.

If it appears that psychiatric attention will be beneficial, the family physician should offer to refer the mother to psychiatric services that are available in all restructured hospitals. Subspecialised services for maternal emotional and mental health are also offered at $\mathrm{KKH}$ and National University Hospital.

\section{TAKE HOME MESSAGES}

1. Persistent attachment difficulties in mother-child dyads, as well as maternal mental health problems, can lead to long-term consequences for the child's mental health and development.

2. Red flags for dysfunction in mother-child dyads include reduced maternal attunement, reduced child responsiveness to the mother, and restricted child growth and development.

3. The family physician can screen for dysfunction in the mother-child dyad and maternal depression during scheduled well-child visits.
4. Early identification of maternal depression facilitates intervention and can translate into positive child outcomes.

5. Resources to support mother-child units include informal help from family and friends, community resources, and specialist psychiatric services.

You noted Sara's blunted maternal affect and reduced material response to the child's cries. Further history-taking revealed stressors including marital conflict and financial distress. Sara acknowledged that she often feels 'down'. You gently suggested some tips on self-care and referred Sara to the postnatal depression intervention programme at KK Women's and Children's Hospital and the Family Service Centre for financial assistance and marital counselling. Sara and Adam returned six months later for Adam's 18-month-old developmental assessment. This time, Sara chatted with you while keeping watch on Adam as he happily explored your room. Adam discovered a stray tongue depressor and triumphantly turned to show it to Sara, who smiled encouragingly before firmly instructing him to return it to you. You found that Adam met all developmental milestones and gladly shared this with Sara as a form of affirmation. 


\section{ACKNOWLEDGEMENTS}

The authors wish to acknowledge Dr How Choon How for his invaluable thoughts and feedback in the writing of this paper.

ABSTRACT Infant social, emotional and neurological development is shaped by the mother-child dyad. Dysfunction in this bond, as well as maternal mental health problems, can negatively impact child development. The family physician is well-placed to spot dysfunction in the mother-child dyad and screen for postnatal depression during well-child visits. If any issues are identified, the family physician can provide support and help the mother-child dyad to access community resources and specialist psychiatric services.

Keywords: child development, postnatal depression, well-child visit

\section{REFERENCES}

1. Sorce JF, Emde RN, Campos JJ, Klinnert MD. Maternal emotional signaling: Its effect on the visual cliff behavior of one-year-olds. Dev Psychol 1985; 21:195-200.

2. Sorce J, Emde RN. Mother's presence is not enough: Effect of emotiona availability on infant exploration. Dev Psychol 1981; 17:737-45.

3. Tsotsi S, Borelli JL, Abdulla NB, et al. Maternal sensitivity during infancy and the regulation of startle in preschoolers. Attach Hum Dev 2018; 8:1-18.

4. Ostlund BD, Measelle JR, Laurent HK, Conradt E, Ablow JC. Shaping emotion regulation: attunement, symptomatology, and stress recovery within motherinfant dyads. Dev Psychobiol 2017; 59:15-25.

5. Winnicott DW. Transitional objects and transitional phenomena; a study of the first not-me possession. Int J Psychoanal 1953; 34:89-97.

6. Shorey S, Chee CYI, Ng ED, Chan YH, Tam WWS, Chong YS. Prevalence and incidence of postpartum depression among healthy mothers: A systematic review and meta-analysis. J Psychiatr Res 2018; 104:235-48.

7. Murray L, Fiori-Cowley A, Hooper R, Cooper P. The impact of postnatal depression and associated adversity on early mother-infant interactions and later infant outcome. Child Dev 1996; 67:2512-26.

8. Lovejoy MC, Graczyk PA, O'Hare E, Neuman G. Maternal depression and parenting behaviour: a meta-analytic review. Clin Psychol Rev 2000; 20:561-92.

9. Moore T, Arefadib N, Deery A, West S. The First Thousand Days: An Evidence Paper [online] 2017. Available at: http://www.rch.org.au/uploadedFiles/ Main/Content/ccchdev/CCCH-The-First-Thousand-Days-An-Evidence-PaperSeptember-2017.pdf. Accessed August 11, 2019.

10. Netsi E, Pearson RM, Murray L, Cooper P, Craske MG, Stein A. Association of persistent and severe postnatal depression with child outcomes. JAMA Psychiatry 2018; 75:247-53.

11. Surkan PJ, Kennedy CE, Hurley KM, Black MM. Maternal depression and early childhood growth in developing countries: systematic review and meta-analysis. Bull World Health Organ 2011; 89:608-15.

12. Bornstein MH, Suwalsky JTD, Breakstone DA. Emotional relationships between mothers and infants: knowns, unknowns, and unknown unknowns. Dev Psychopathol 2012; 24:113-23.

13. Wong PY, How CH, Wong P. Management of child abuse. Singapore Med I 2013; 54:533-7.

14. Earls MF; Committee on Psychosocial Aspects of Child and Family Health American Academy of Pediatrics. Incorporating recognition and management of perinatal and postpartum depression into pediatric practice. Pediatrics 2010; 126:1032-9.

15. Gagliardi A, Honigfeld, L. Addressing Maternal Depression: Opportunities in the Pediatric Setting. Connecticut: Child Health and Development Institute of Connecticut, 2008.

16. Umboh SJ, How $\mathrm{CH}$, Chen $\mathrm{H}$. Postnatal depression: a family medicine perspective. Singapore Med J 2013; 54:477-81.

17. Lee TM, Bautista D, Chen HY. Understanding how postnatal depression screening and early intervention work in the real world - a Singaporean perspective. Ann Acad Med Singapore 2016; 45:466-70. 


\section{SINGAPORE MEDICAL COUNCIL CATEGORY 3B CME PROGRAMME}

\section{(Code SMJ 201910A)}

1. The mother-child dyad share an intimate biological, social and psychological relationship.

2. Infant social, emotional and neurological development is influenced by maternal emotional availability, maternal sensitivity and responsiveness to infant cues.

3. When exploring an unfamiliar situation, infants look to their parents' responses and emotional expressions as guides in approaching or withdrawing from stimuli.

4. Mothers do not need to be perfect, just 'good enough' to provide a secure base for their children.

5. One in 100 mothers experience postpartum depression.

6. Mothers with depression can be less attuned to their infant's needs, less responsive to infant cues, and display more negative, hostile or disengaged parenting behaviours.

7. Maternal depression affects an eight-year-old child as much as it does a six-month-old infant.

8. Children of mothers with persistent and severe depression are at increased risk of behavioural problems, depression in adolescence and stunted growth.

9. The mother of a child with autism spectrum disorder may display blunted maternal affect and delayed responses to the child's cries. This is a normal response and not a red flag for dysfunction, considering the stress of caring for a child with special needs.

10. No intervention needs to be considered for the child of an adolescent mother who exhibits irritable behaviour and delayed developmental milestones.

11. Reduced child responsiveness to the mother, and restricted child growth and development are red flags that may suggest dysfunction in the mother-child dyad.

12. Socioeconomic circumstances such as low maternal education level, being a single mother or having had an unwanted pregnancy increase the risk of dysfunction in the mother-child dyad.

13. Medical circumstances such as maternal illness and child hearing/visual impairment increase the risk of dysfunction in the mother-child dyad.

14. The family physician can opportunistically identify at-risk mother-child dyads during scheduled well-child developmental assessments and the routine postnatal check.

15. It is inappropriate to assess for dysfunction in the mother-child dyad during ad-hoc consultations for acute illnesses; assessment is inaccurate when the child is sick and the mother stressed.

16. The Patient Health Questionnaire 2 screen for maternal depression is time-consuming and difficult to implement in a busy family practice.

17. Early identification and treatment of mothers with depression can lead to improved maternal and child outcomes.

18. The spouse, family and social network are important sources of support for mother-child dyads.

19. Subspecialist maternal mental health services are available in all restructured hospitals in Singapore.

20. If a mother declines a referral to specialist mental/emotional health services, the family physician can still offer simple tips and refer her to community support services.

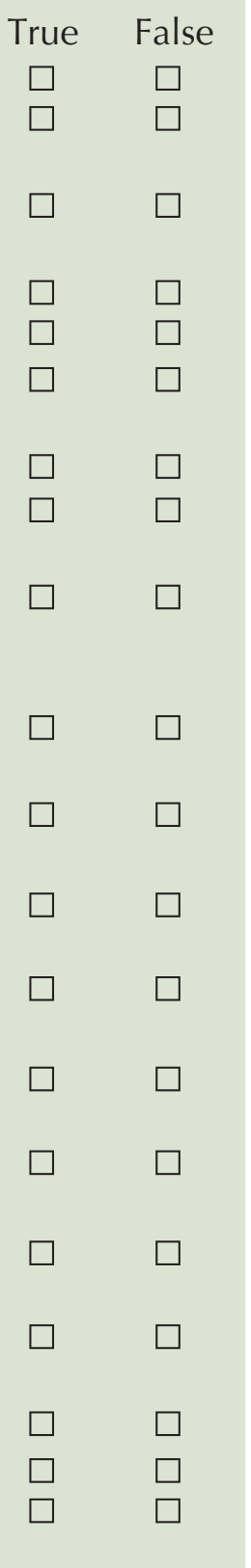

\section{Doctor's particulars:}

Name in full:

MCR no:

Specialty:

Email:

\section{SUBMISSION INSTRUCTIONS}

Visit the SMJ website: http://www.smj.org.sg/current-issue and select the appropriate quiz. You will be redirected to the SMA login page.

For SMA member: (1) Log in with your username and password (if you do not know your password, please click on 'Forgot your password?'). (2) Select your answers for each quiz and click 'Submit'.

For non-SMA member: (1) Create an SMJ CME account, or log in with your SMJ CME username and password (for returning users). (2) Make payment of SGD 21.40 (inclusive of $7 \%$ GST) via PayPal to access this month's quizzes. (3) Select your answers for each quiz and click 'Submit'.

RESULTS

(1) Answers will be published online in the SMJ December 2019 issue. (2) The MCR numbers of successful candidates will be posted online at the SMJ website by 10 December 2019. (3) Passing mark is $60 \%$. No mark will be deducted for incorrect answers. (4) The SMJ editorial office will submit the list of successful candidates to the Singapore Medical Council. (5) One CME point is awarded for successful candidates. (6) SMC credits CME points according to the month of publication of the CME article (i.e. points awarded for a quiz published in the December 2017 issue will be credited for the month of December 2017, even if the deadline is in January 2018).

Deadline for submission (October 2019 SMJ 3B CME programme): 12 noon, 3 December 2019. 